\title{
Photoelastic Stress Response of Complex 3D-Printed Particle Shapes
}

\author{
Negin Amini ${ }^{1}$, Joshua Tuohey ${ }^{1}$, John Long ${ }^{1}$, Jun Zhang ${ }^{1}$, David Morton ${ }^{1}$, Karen Daniels ${ }^{2}$, \\ Farnaz Fazelpour ${ }^{2}$, and Karen Hapgood ${ }^{1}$ \\ ${ }^{1}$ Deakin University - Geelong Waurn Ponds Campus \\ ${ }^{2}$ North Carolina State University
}

March 2, 2021

\begin{abstract}
Stress visualization within 3-dimensional particles undergoing dynamic processes can greatly advance our understanding of complex particle behaviors. Traditional photoelastic stress visualization methods suffer inherent limitations from lack of available technology for complex particle production. Recently, 3D-printing has created new possibilities for enhancing the scope of stress analysis within physically representative granules. Here, we investigate opportunities offered by 3D-printing a granular material with photoelastic properties. We report the results of X-ray computed tomography and 3D-printing, combined with traditional photoelastic analysis, to visualize strain exhibited within simple discs to reproduced coffee beans. We find that the choice of print layer orientation with respect to the force load affects the optical properties of the discs, without a significant difference in their mechanical properties. Furthermore, we present a first, semi-quantified, measurement of stresses within 3D-printed particles of complex shape. The promising data shows potential for applying this method to complex assemblies of 3-dimensional particles.
\end{abstract}

\section{Hosted file}

Deakin_photoelasticity_for submission(withoutimages).pdf available at https://authorea. com/users/399145/articles/511699-photoelastic-stress-response-of-complex-3d-printedparticle-shapes

\section{Hosted file}

Table 1.pdf available at https://authorea.com/users/399145/articles/511699-photoelasticstress-response-of-complex-3d-printed-particle-shapes

\section{Hosted file}

Table 2.pdf available at https://authorea.com/users/399145/articles/511699-photoelasticstress-response-of-complex-3d-printed-particle-shapes 

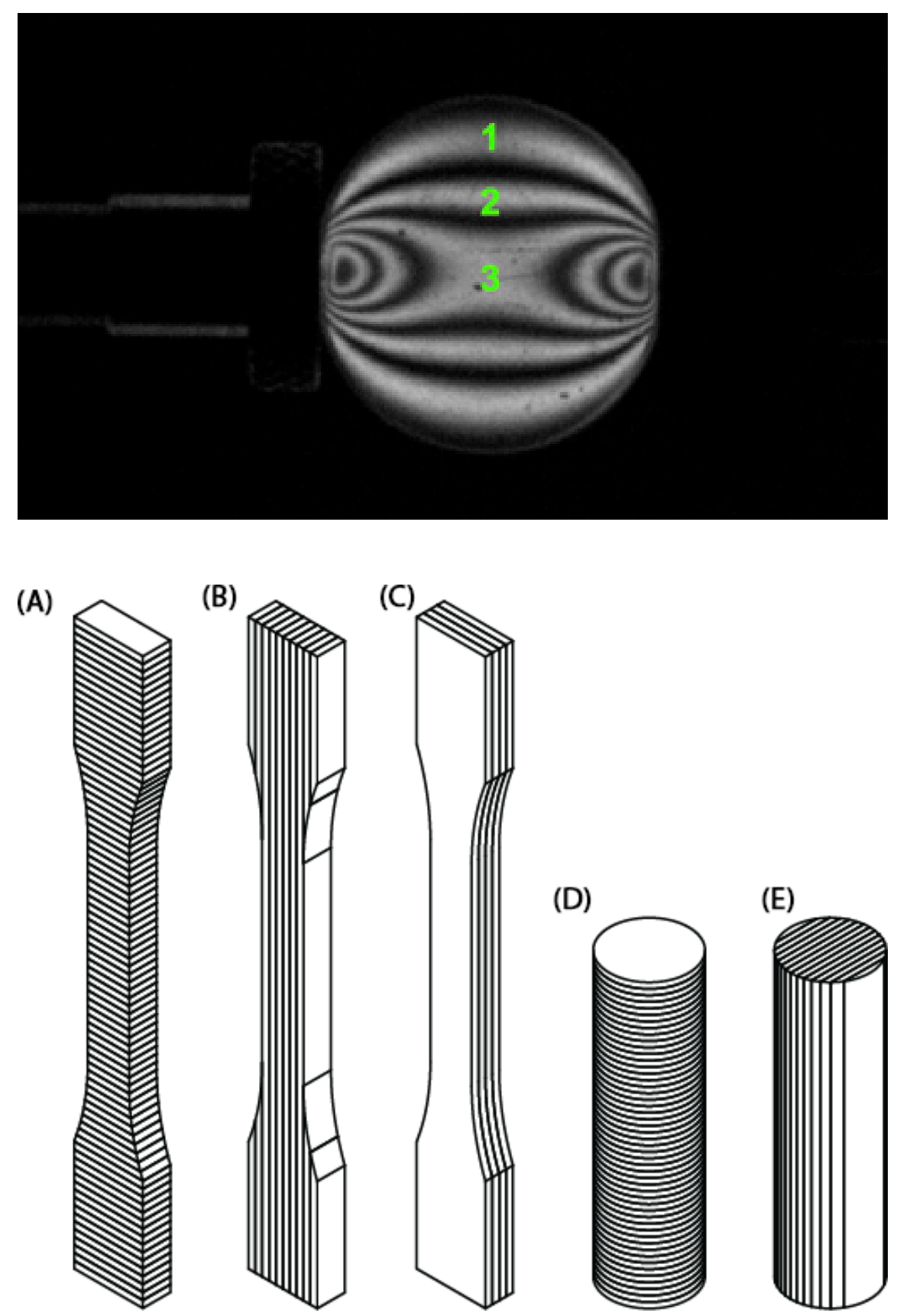

(B)

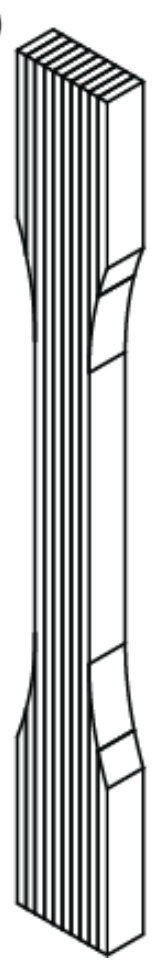

(C)

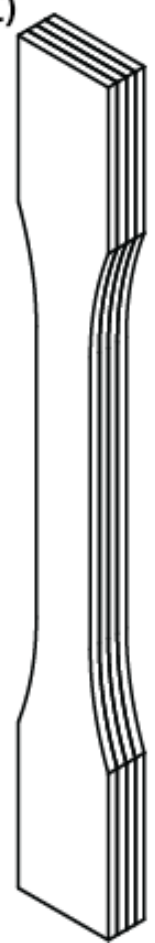

(D)

(E)
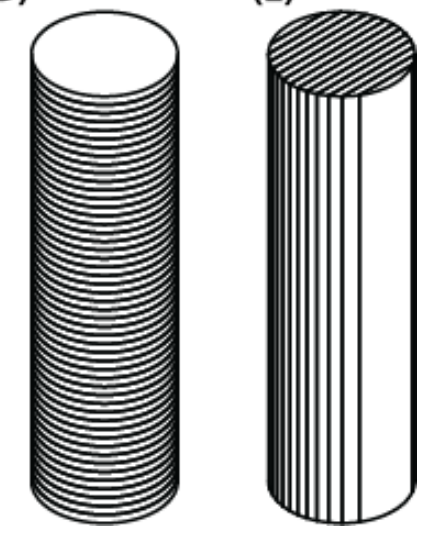

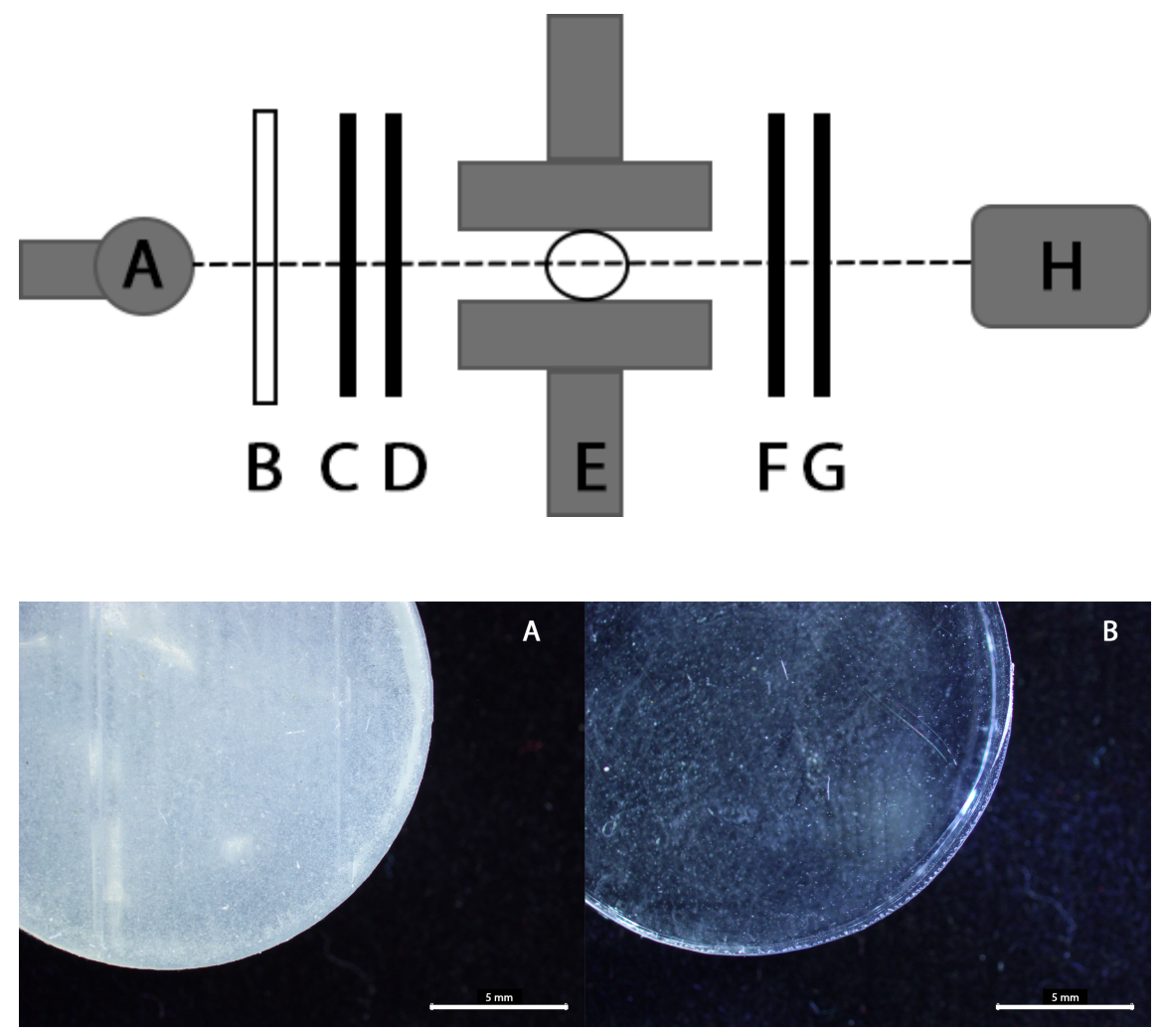

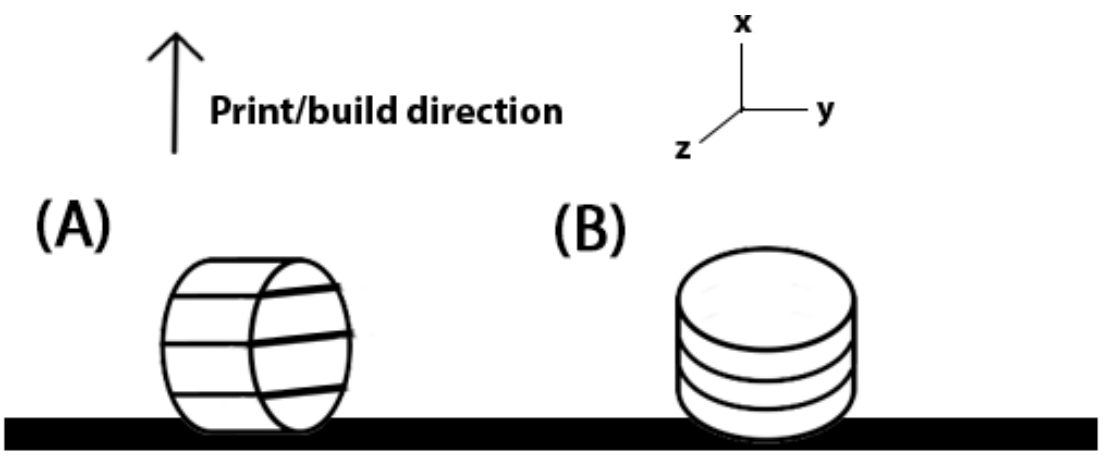

3D-printing build platform
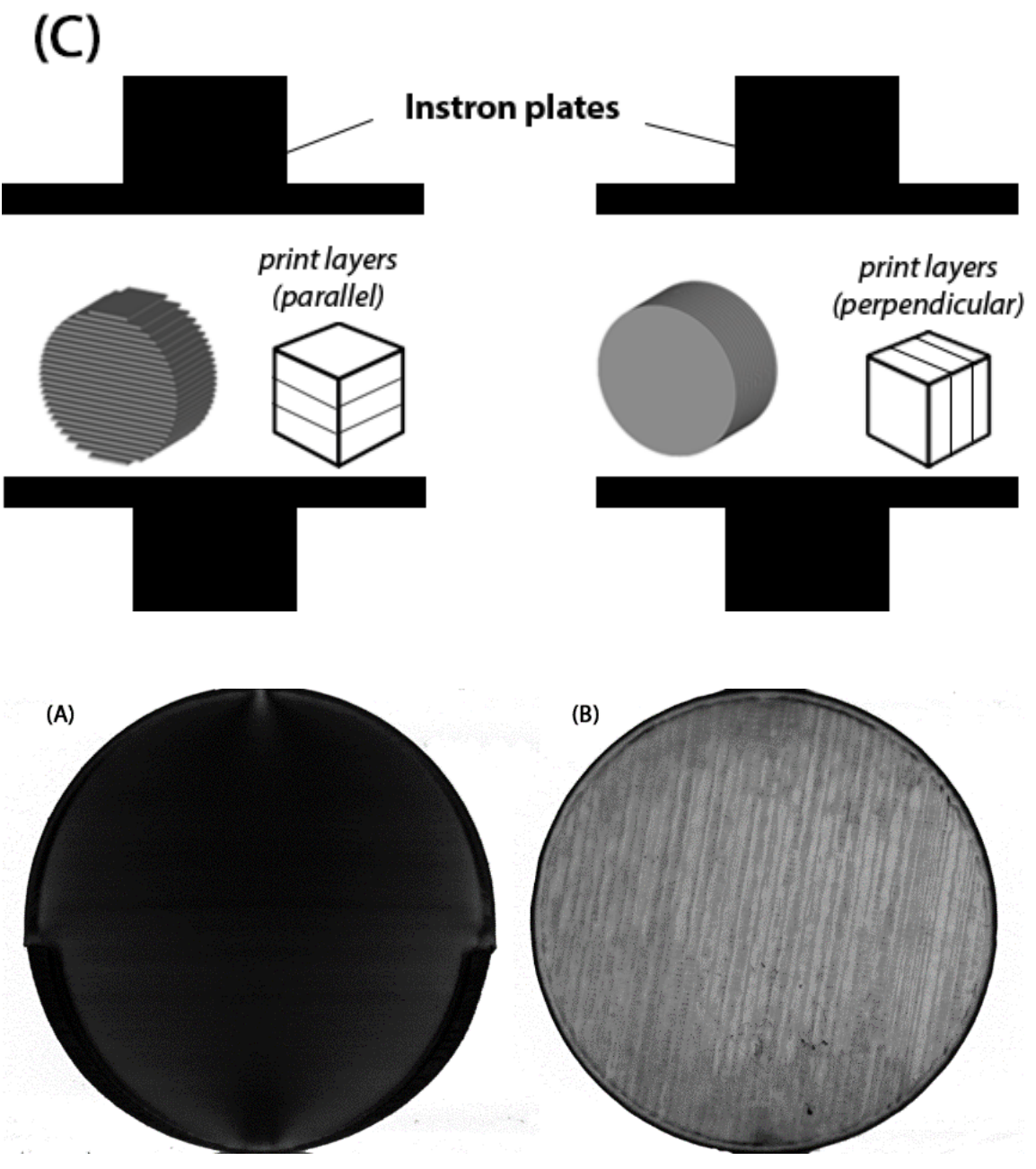

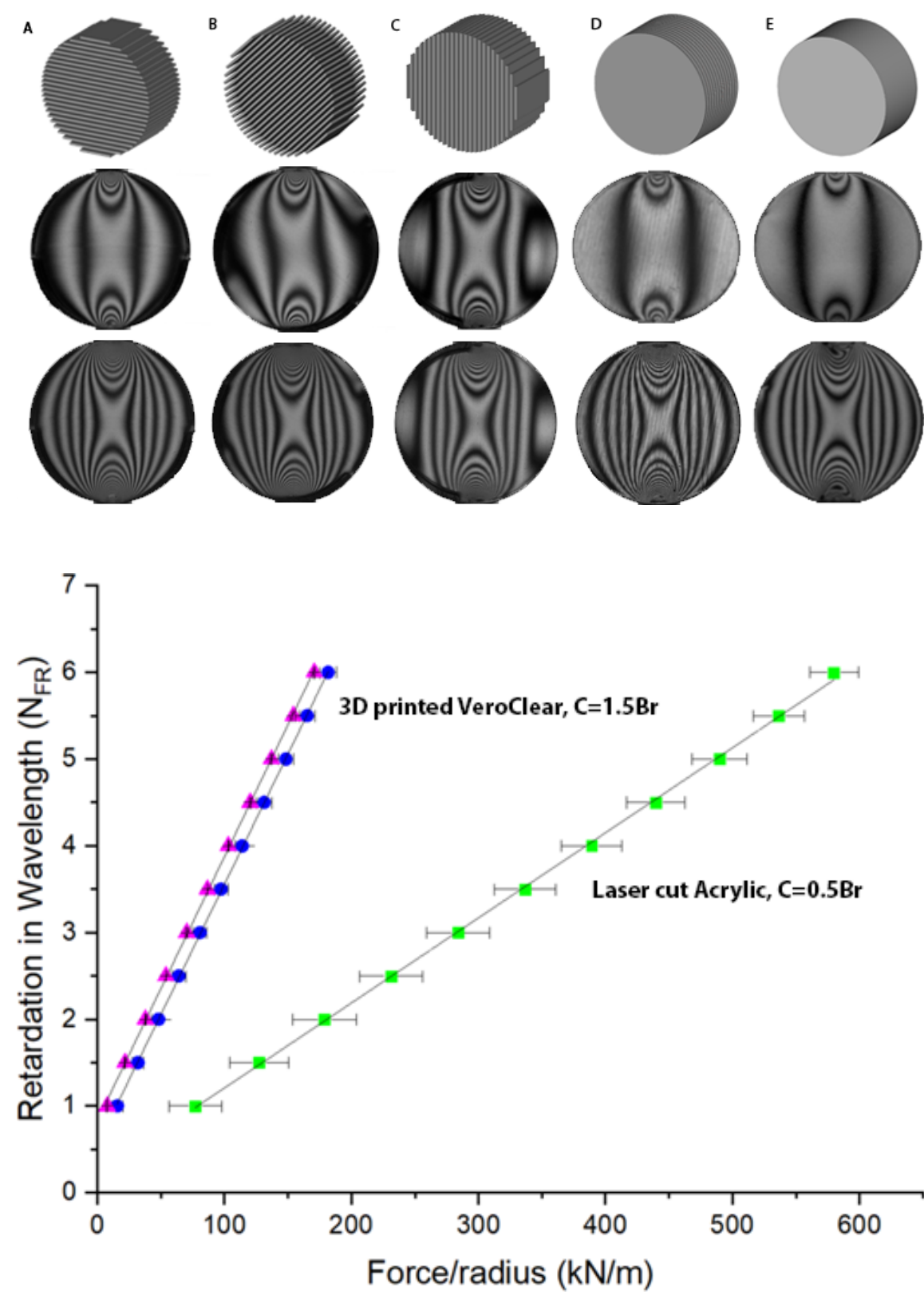

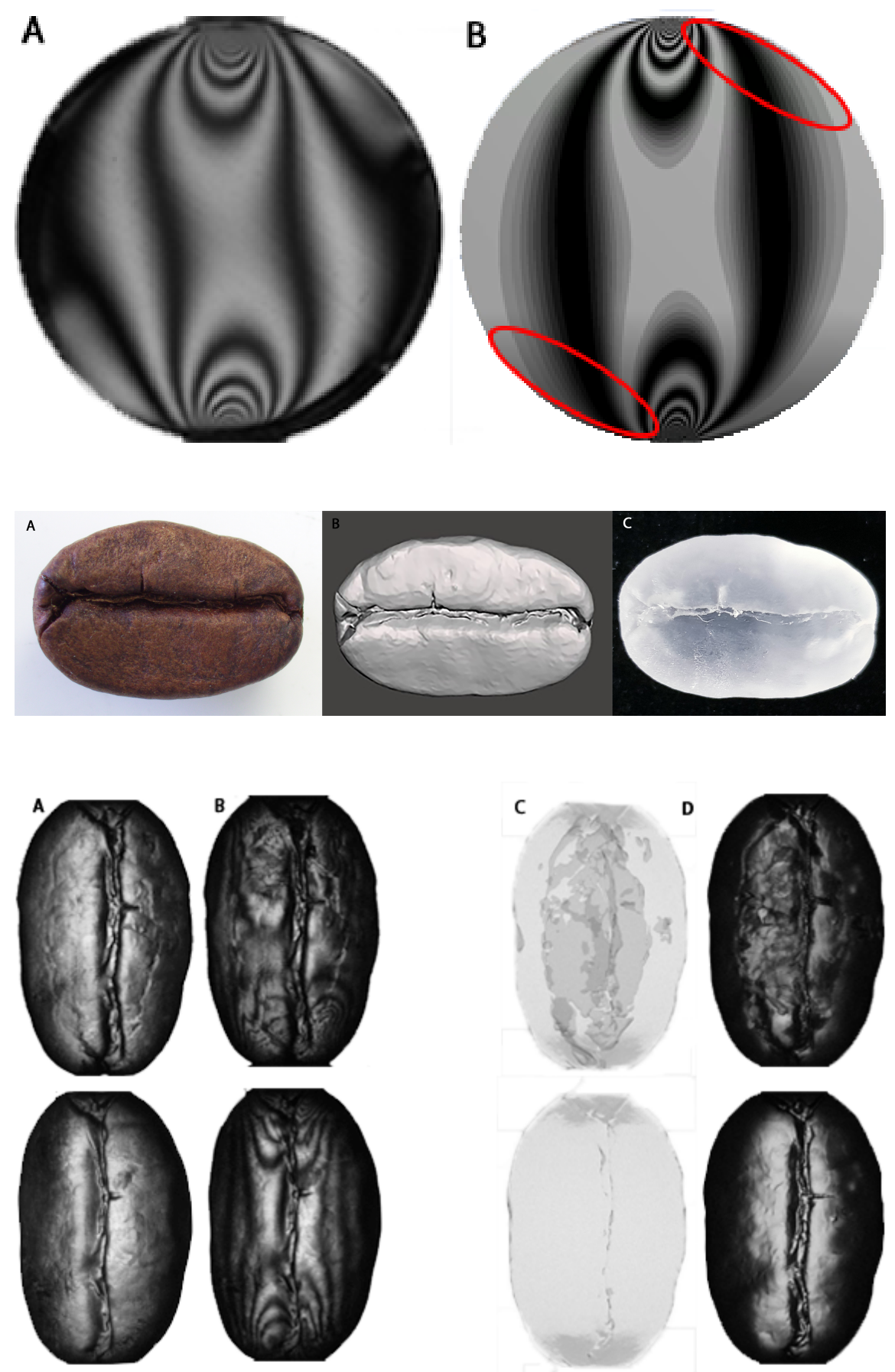

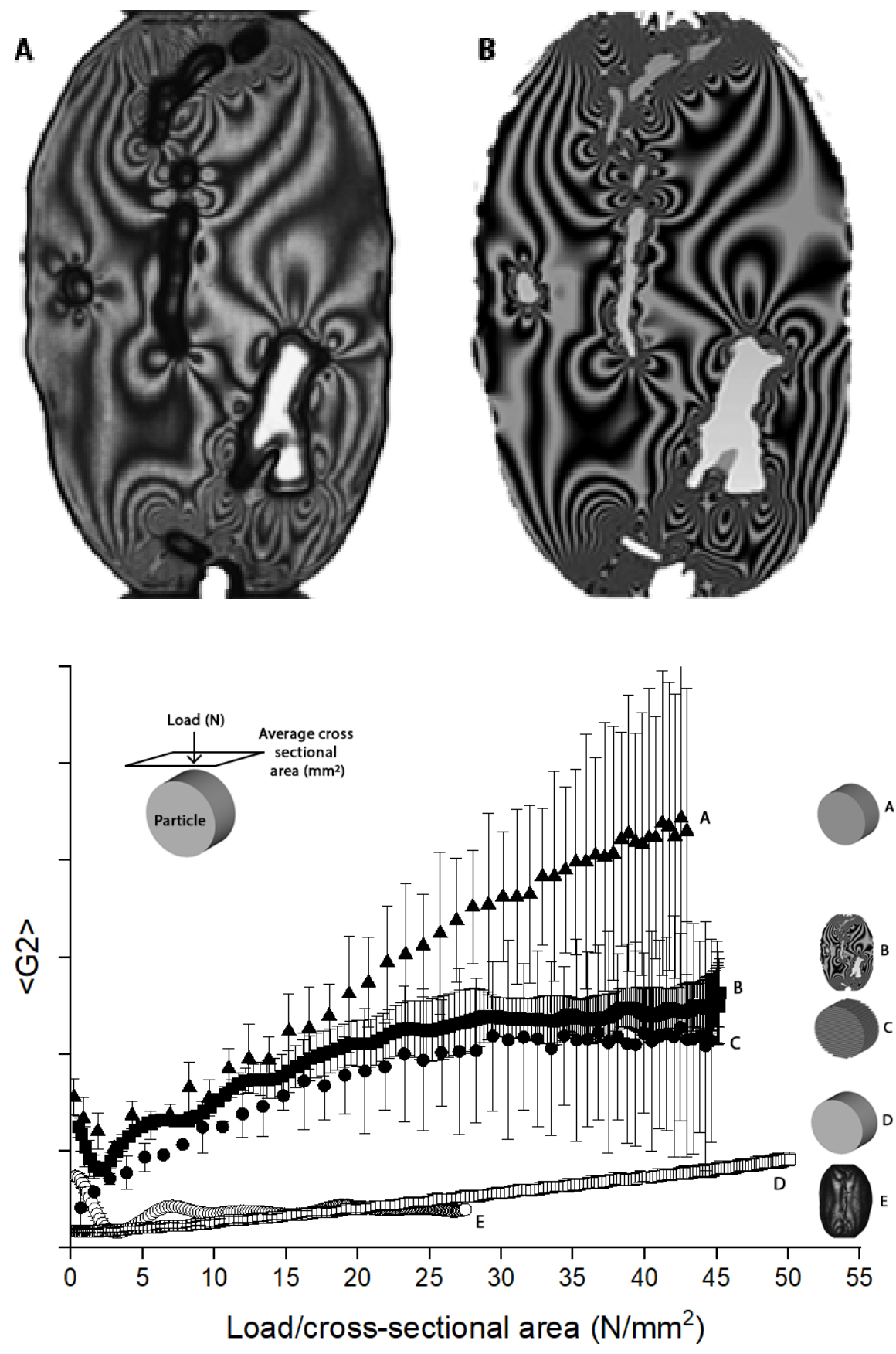